\title{
Transcutaneous Oxygen and Carbon Dioxide during the First Half Year of Life in Premature and Normal Term Infants
}

\author{
TOKE HOPPENBROUWERS, JOAN E. HODGMAN, KAZUKA ARAKAWA, MANUEL DURAND, \\ AND LUIS A. CABAL \\ Department of Pediatrics, University of Southern California School of Medicine and Los Angeles County/ \\ University of Southern California Medical Center, Los Angeles, California 90033
}

\begin{abstract}
Repetitive polysomnograms were recorded from a total of 33 infants, 19 healthy preterm infants, and 14 term controls between 40 wk postconceptional age and 6 mo of age. These nighttime recordings lasted $2-4 \mathrm{~h}$, except at $52 \mathrm{wk}$ in preterm infants and at $3 \mathrm{mo}$ of age in term infants when an overnight 12 -h recording was performed. Minute by minute values of transcutaneous $\mathrm{PO}_{2}$ $\left(\mathrm{PtcO}_{2}\right)$ and transcutaneous $\mathrm{PCO}_{2}\left(\mathrm{PtcCO}_{2}\right)$ levels and variability during the awake state, active sleep, and quiet sleep were obtained through computer analyses of the polygraphic data. The results from preterm infants at corrected postconceptional age could not be differentiated from those of control infants. $\mathrm{PtcO}_{2}$ levels rose between 40 wk and 3 mo, and $\mathrm{PtcCO}_{2}$ levels declined. Sleep states modulated only the variability of $\mathrm{PtcO}_{2}$, not the level; in contrast, state modulation was seen in both variability and level of $\mathrm{PtcCO}_{2}$ throughout the age span studied. During sleep the number of transient declines in $\mathrm{PtcO}_{2}>2.03 \mathrm{kPa}(15 \mathrm{~mm} \mathrm{Hg})$ decreased with advancing age. Hypercapnic $\mathrm{PtcCO}_{2}$ values decreased with age as well, but their prevalence in healthy, young infants suggests the need for reevaluation of criteria for hypercapnia based on transcutaneous measurements. The data demonstrate that ventilatory regulation continues to undergo changes between 1 and 3 mo, the age of highest risk for sudden infant death syndrome. (Pediatr Res 31: 73-79, 1992)
\end{abstract}

\section{Abbreviations}

$\mathrm{PtcO}_{2}$, transcutaneous $\mathrm{PO}_{2}$

$\mathrm{PtcCO}_{2}$, transcutaneous $\mathrm{PCO}_{2}$

PCA, postconceptional age

AS, active sleep

QS, quiet sleep

AW, awake

With the onset of pulmonary ventilation after birth, arterial $\mathrm{PO}_{2}$ levels rapidly rise from the $2.7-4.1 \mathrm{kPa}(20-30$ torr) characteristic of the fetus to approximately $8.1-9.5 \mathrm{kPa}(60-70$ torr), but $\mathrm{PCO}_{2}$ levels do not change dramatically (1). During the first weeks of life, $\mathrm{PCO}_{2}$ sensitivity increases slowly and $\mathrm{PCO}_{2}$ threshold decreases with age as evidenced by a displacement of the $\mathrm{PCO}_{2}$

\footnotetext{
Received March 13, 1991; accepted July 24, 1991.
}

Correspondence: Toke Hoppenbrouwers, Ph.D., Director, Sudden Infant Death Syndrome Research Project, Rm 9L19 Women's Hospital, LAC/USC Medical Center, 1240 Mission Rd., Los Angeles, CA 90033.

Supported by NICHD Grant 13689 , the Orange County Chapter of the Guild for Infant Survival, The Los Angeles Chapter of the National SIDS Foundation, and the Arthur Zimtbaum Foundation of New York. response curve and a change in its slope (2). The best documented example of change with age is probably the immature biphasic response to hypoxia, in which an initial increase in ventilation is followed almost immediately by a decrease to lower than baseline levels. This contrasts with the more mature pattern attained before 1 mo of age, when the infant manages to sustain an increase in ventilation throughout the hypoxic challenge $(3,4)$.

With the advent of transcutaneous monitoring, a noninvasive tool to follow normal changes in $\mathrm{PO}_{2}$ and $\mathrm{PCO}_{2}$ during the first months of life became available (5). This technique has been successfully used to measure $\mathrm{PO}_{2}$ in the fetus and newborn (6-9) and in older infants (10-17). Fewer studies have thus far dealt with $\mathrm{PtcCO}_{2}$ in term and preterm infants $(10,11,18)$. None of the studies of either $\mathrm{PtcO}_{2}$ or $\mathrm{PtcCO}_{2}$ used computer analysis of longitudinal polygraphic data. The present report describes postnatal changes in $\mathrm{PtcO}_{2}$ and $\mathrm{PtcCO}_{2}$ thus obtained in preterm infants and healthy term control infants during the first 6 mo of life. The modulating effect of sleep and waking states was an integral part of the analysis.

\section{MATERIALS AND METHODS}

Material and monitoring procedure. Fourteen normal subjects were selected during the last trimester of pregnancy, for study after birth, based on the absence of disease in their mothers. This group consisted of nine females and five males.

In addition, 19 appropriate-for-gestational-age preterm infants were selected in the nursery when they were between 32 and 36 wk PCA. Infants were excluded if they had received assisted ventilation for more than $24 \mathrm{~h}$ or supplemental oxygen for more than $48 \mathrm{~h}$ except for treatment of apnea. All medical conditions such as intracranial hemorrhage of grades III and IV and culture proven sepsis were also excluded. This preterm group consisted of five females and 14 males. Of these, nine exhibited two or more episodes of apnea $>20$ s during an 8 -h period beyond the first week of life. Because $\mathrm{PtcO}_{2}$ and $\mathrm{PtcCO}_{2}$ were not significantly different upon follow-up, irrespective of the presence of previous apneic episodes, the data from these preterm infants reported in detail elsewhere (19) were combined and included here for comparison with those of term infants.

Our protocol was approved by the Los Angeles County/University of Southern California Medical Center Human Research Committee, and informed consent was obtained before each session. The study design called for repetitive laboratory monitoring after discharge from the hospital at 40, 44, and $52 \mathrm{wk}$ PCA for the preterm group, and at 1,3, and 6 mo of age for the term groups. Eighteen preterm infants returned to the sleep laboratory at $40 \mathrm{wk}$ PCA, and 17 returned at 44 wk PCA. Only 10 parents were willing to return the infants for laboratory monitoring at $52 \mathrm{wk}$ of age. For the controls the polygraphic recording schedule was adhered to. 
Each infant was admitted to the sleep laboratory between 1700 and $1800 \mathrm{~h}$ for 2- to $4-\mathrm{h}$ recordings, except at $3 \mathrm{mo}$ or $52 \mathrm{wk}$, when 22 infants were monitored for $10-12 \mathrm{~h}$ overnight. The session began with a short physical and neurologic evaluation. The infants were fed during preparation for monitoring and application of electrodes, whereafter a demand feeding schedule was followed. Occasionally during an overnight recording the infant was breast-fed. Arm restraints were applied before the initiation of recording. Monitoring was carried out in a darkened room adjacent to the room containing the recording equipment. Although room temperatures ranged between 19.3 and $26.4^{\circ} \mathrm{C}$, infants in each group were exposed to comparable temperatures, with the group means ranging between 21 and $22^{\circ} \mathrm{C}$. The infants were placed in a supine or side-lying position and observed continuously with the help of a low-illumination television camera and monitor. Activities such as closing and opening of the eyes, startles, crying, and nursing interventions were charted on the polygraph paper (20).

Physiologic recording methods. Sleep variables included two EEG derivations (approximately $\mathrm{C} 1-\mathrm{C} 5$ and $\mathrm{C} 2-\mathrm{C} 6$, according to the International 10-20 system), a chin electromyogram, and eye movements. Electrodes on the mattress surface under the crib sheet registered the infant's body movements. Thoracic and abdominal excursions were monitored by strain gages, and a $\mathrm{PCO}_{2}$ monitor (Beckman Instruments, Inc., Palo Alto, CA) sampled expired gas through a miniature cannula taped under the infant's nostrils. The ECG was recorded with two disposable electrodes placed beneath the clavicles. Additionally, a skin temperature probe was applied to the abdomen below the right costal margin (20).

$\mathrm{PtcO}_{2}$ and $\mathrm{PtcCO}_{2}$ were measured with a Novametrix (Wallingford, CT) monitor. The $\mathrm{O}_{2}$ and $\mathrm{CO}_{2}$ electrodes were taped to the right and left upper chest, respectively. An $\mathrm{O}_{2}$ electrode temperature of $43.5^{\circ} \mathrm{C}$ was selected, and during a 12-h recording the electrode placement was altered by several millimeters at $4-$ to 6 -h intervals. The $\mathrm{CO}_{2}$ electrode was unheated. Both electrodes were calibrated at the onset and termination of each monitoring session or at 4- to 6-h intervals with gases of known $\mathrm{O}_{2}$ and $\mathrm{CO}_{2}$ concentration [ 0 and $12.4 \mathrm{kPa}(92 \mathrm{~mm} \mathrm{Hg})$ for $\mathrm{O}_{2} ; 5.1$ and 10.3 $\mathrm{kPa}\left(38\right.$ and $76 \mathrm{~mm} \mathrm{Hg}$ ) for $\mathrm{CO}_{2}$ ]. Humidity of the room air was sampled on an hourly basis during the monitoring and was comparable in each study group.

The data were recorded on a 16-channel model 76 polygraph (Grass Instrument Co., Quincy, MA) at $6 \mathrm{~mm} / \mathrm{s}$ paper speed and on an eight-channel Brush recorder (Gould, Inc., Cleveland, $\mathrm{OH}$ ) at $1 \mathrm{~cm} / \mathrm{min}$ paper speed and stored simultaneously with a time code on a 14-channel analog tape recorder (Honeywell Inc., Van Nuys, CA).

Data analysis. The polygraphic tracings were coded by trained observers into minutes of AS, QS, AW, and indeterminate sleep, according to generally accepted criteria described elsewhere (21). Every 50 th min of the recording was recoded by an independent observer to ensure an agreement between coders of at least $80 \%$. Minutes of indeterminate sleep were not further used for analysis because of low interrater reliability.

Data on the analog tapes were digitized by a preprocessing microcomputer with eight channels of analog to digital interface (22). The sampling rate was $1 / \mathrm{s}$ for $\mathrm{PtcO}_{2}$ and $\mathrm{PtcCO}_{2}$. Several steps were taken to reduce contamination of the data by artifact: First, each minute of the computer output was scanned for abnormal values with the polygraphic recording used as an ultimate reference. Second, the magnitude of the electrode drift was measured by comparing initial and end calibrations. If the drift between the onset and end calibrations equalled or exceeded $0.68 \mathrm{kPa}(5 \mathrm{~mm} \mathrm{Hg})$, the minute by minute values were adjusted by the formula $m(\operatorname{adj})=m-(a+b m) t$ (see Appendix $)$. This formula assumes that the drift is linear, an assumption that did not bias the data in favor of any of the sleep state, study, or age groups. The $\mathrm{PtcCO}_{2}$ values were further adjusted by the formula
$\mathrm{PtcCO}_{2}=1.14$ arterial $\mathrm{PCO}_{2}+4.88$, to better reflect arterial values (23).

Sleep state classifications were then integrated with the computer data and together plotted on a minute by minute basis (Fig. 1). In addition, a 10 -min moving average was generated to better allow visualization of the interrelationship between variables (Fig. 2). For every minute, the number of times the $\mathrm{PtcO}_{2}$ was two SD lower than the mean for that minute was also determined. For $\mathrm{PtcCO}_{2}$ the same value was calculated as well as the times the $\mathrm{PtcCO}_{2}$ reached two SD above the mean. The tracings were also scanned visually for the presence of transient decreases in $\mathrm{PtcO}_{2}$ in excess of $2.03 \mathrm{kPa}(15 \mathrm{~mm} \mathrm{Hg})$. Because the $\mathrm{PtcO}_{2}$ signal varies widely during wakefulness, this analysis was restricted to periods when the infant was asleep. Computergenerated minute by minute mean values of $\mathrm{PtcCO}_{2}$ levels in excess of $6.75 \mathrm{kPa}$ (50 torr) were identified for each infant and each sleep state as well.

The means of all the minute to minute data of $\mathrm{PtcO}_{2}$ and $\mathrm{PtcCO}_{2}$ levels and variability were obtained for each infant, and the data were compared as a function of study group, age, and sleep state, with the aid of an analysis of variance (BMD P4V) or a $t$ test (24).

\section{RESULTS}

Clinical findings. Clinical characteristics are provided in Table 1. The controls were of low obstetric risk with only one complication: a prolonged second stage labor. There was a higher incidence of complications in the mothers of preterm infants, as would be expected, with seven of 19 exhibiting such problems as preeclampsia and amnionitis. All infants were appropriate for gestational age, in good condition at birth, and few had nursery complications. The preterm group was specifically selected for absence of neonatal problems.

On follow-up of control infants, abnormal physical findings were limited to transient neurologic abnormalities and sporadic evidence of upper respiratory infections. Approximately half of the prematures were readmitted to the hospital after nursery discharge, usually for treatment of infection. When last seen, growth was normal in infants of both study groups. With one exception in the preterm apneic group, all infants exhibited normal developmental progress as well.

Sleep and waking. Monitoring of $\mathrm{PtcO}_{2}$ requires repositioning of the heated electrode and precludes undisturbed sleep during the night. Therefore, the overnight tracings were not suited to ascertain the presence of detailed sleep and wakefulness differences between infants. For the same reason, they were unsuited to reveal a circadian modulation of $\mathrm{PtcO}_{2}$ and $\mathrm{PtcCO}_{2}$ levels in the 3-mo-old and 52-wk-old infants' overnight recordings.

As reported elsewhere (19), the amounts of sleep and waking in preterm infants with and without apnea in the nursery could with one exception not be differentiated. The exception was found at $44 \mathrm{wk}$ in the preterm group, where the infants who had experienced prolonged apnea in the neonatal period had more $\mathrm{AS}$ and fewer awakenings than the preterm infants who had not experienced apnea. There were no other significant differences in the percentages of QS, AS, and AW between control and preterm infants at their corrected ages (Table 2).

Transcutaneous gases. A representative sample of the transcutaneous tracings shows variations in $\mathrm{PtcO}_{2}$ and $\mathrm{PtcCO}_{2}$ on a minute by minute basis (Fig. 3).

Comparison of preterm and term control infants. When the values of the total preterm group at 44 and 52 wk PCA were compared with those of the term control group at the comparable ages of 1 and $3 \mathrm{mo}$, no differences were observed in the level and variability of either $\mathrm{PtcO}_{2}$ or $\mathrm{PtcCO}_{2}$ (Table 3 ).

$\mathrm{PtcCO}_{2}$ levels in excess of $6.75 \mathrm{kPa}$ (50 torr) were seen in 35 , 29 , and $9 \%$ of the preterm infants at 40,44 , and $52 \mathrm{wk}$, respectively. Comparable values for the term control group were 33,10 , and $7.6 \%$ at 1,3 , and 6 mo. 


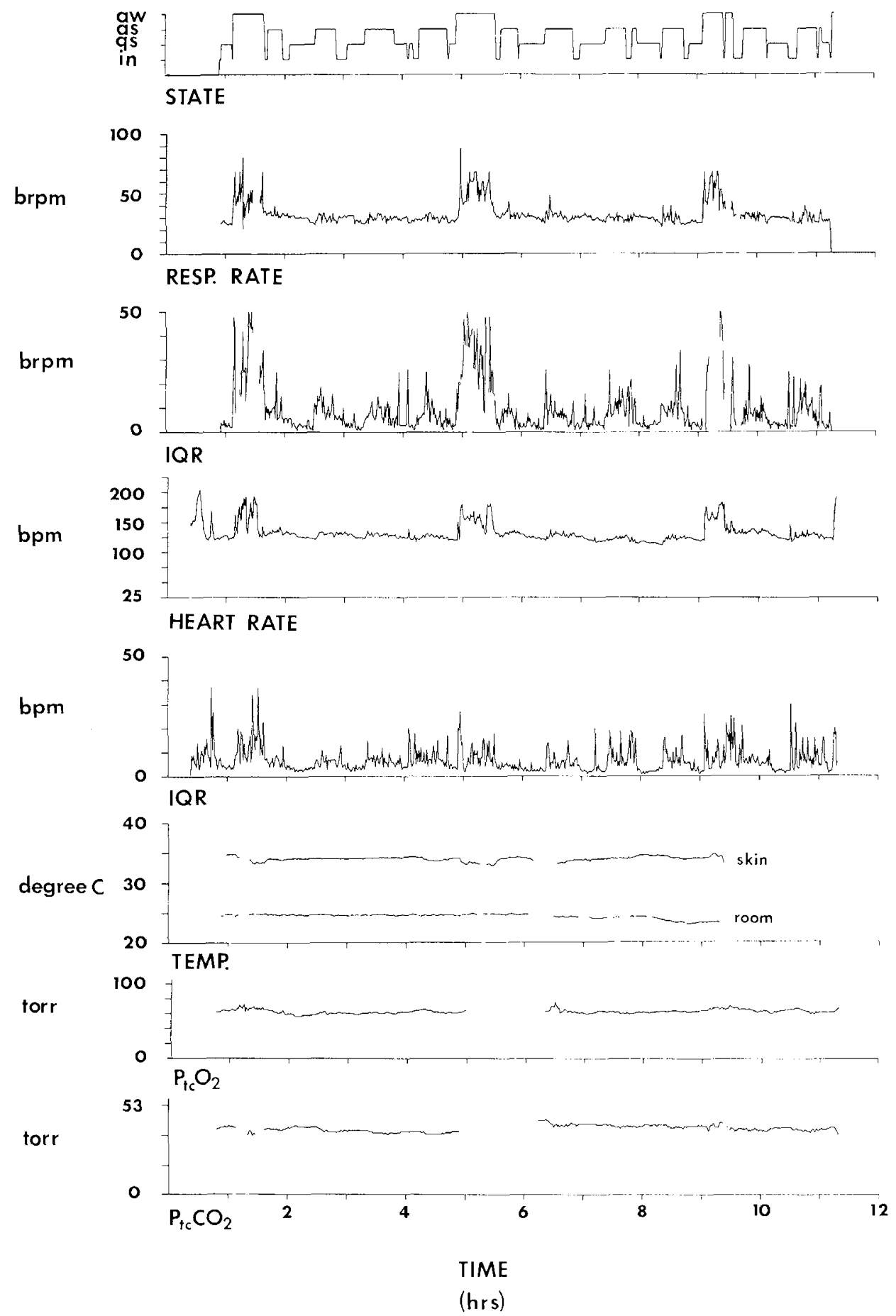

Fig. 1. Plot of minute by minute values of breathing, cardiac activity, temperature, and transcutaneous gases during sleep and waking in an overnight recording of a 3-mo-old control infant. Missing $\mathrm{PtcO}_{2}$ and $\mathrm{PtcCO}_{2}$ data are due to change of electrodes, recalibration, and stabilization. Note the obvious sleep state modulation in cardiac and respiratory variability, but its absence in $\mathrm{PtcO}_{2}$ level. $I Q R$, interquartile range; brpm, breath per minute; $b p m$, beats per minute; $a w$, awake; $a s$, active sleep; $q s$, quiet sleep; in, indeterminate; 100 torr $=13.5 \mathrm{kPa} ; 53$ torr $=7.16 \mathrm{kPa}$.

Transcutaneous gases as function of age. In preterm infants a significant age effect in $\mathrm{PtcO}_{2}$ level was observed in all states (QS: $F=8.78$, df $2,5, p<0.03 ;$ AS: $F=88.76$, df $2,5, p<0.0001$ AW: $F=9.16, d f 2,5, p<0.03$ ). This represents a rise in $\mathrm{PtcO}_{2}$ level between 40 and $52 \mathrm{wk}$ in these infants (Fig. 4). A significant age effect was also observed when the two groups were combined $(F=6.64, d f 1,26, p<0.02)$. The rise in $\mathrm{PtCO}_{2}$ levels with age was seen in every state, including AW (Table 3 ). Over the entire age range, the lowest mean values were observed at $40 \mathrm{wk}$ in preterm infants $[8.78+1.0(65$ torr +7.7$)]$ and the highest mean values were seen in the same infants at $52 \mathrm{wk}[10.8+1.3(80$ torr +9.3$)$ ]. The $\mathrm{PtcO}_{2}$ variability declined with age in all states.
Transient drops in $\mathrm{PtcO}_{2}$ as measured by deviations in excess of two SD from the mean for that minute occurred on the average between 1.0 and 1.3 times per min at every age in both preterm and term control infants. The range of such events per min varied between 0 and 8 in preterm infants but could be as high as 12 in term control infants. There was no correlation between sleep states and the maximum number of these relative drops.

The number of infants showing visually observed transient declines in $\mathrm{PtcO}_{2}>2.03 \mathrm{kPa}(15 \mathrm{~mm} \mathrm{Hg})$ decreased between 3 and $6 \mathrm{mo}$. These episodes were seen in $22 \%$ of the preterm 


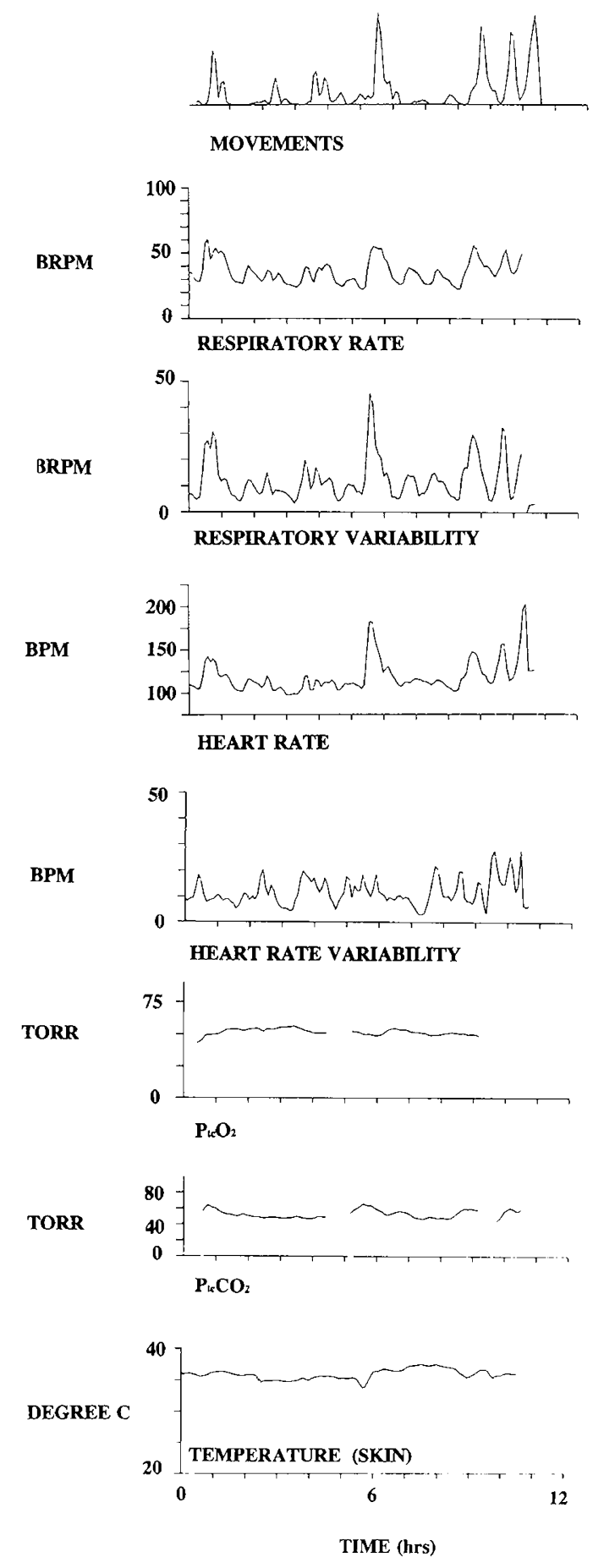

Fig. 2. Ten-min moving average of the same variables as in Figure 1, this time from a 52 -wk-old preterm infant. Movements have been substituted for sleep and waking states. Blood gas values at adjusted ages cannot be distinguished from those of term infants. Abbreviations are the same as in Figure $1(40$ torr $=5.4 \mathrm{kPa} ; 75$ torr $=10.13 \mathrm{kPa})$.

infants at $40 \mathrm{wk}$ (range $1-16$ ), 38\% at $44 \mathrm{wk}$ (range 1-4), and $9 \%$ of the infants at 52 wk (only one infant with one decrease). In term control infants, such decreases were observed in $29 \%$ of infants at 1 mo (range 1-2), 7\% at 3 mo (only one infant with one decrease), and none at 6 mo. Thus, at comparable ages, there were no differences between term control and preterm infants.

The rise in $\mathrm{PtcO}_{2}$ was accompanied by a significant decline in mean $\mathrm{PtcCO}_{2}$ levels during the first 3 mo of life, again in all states (AS: $p<0.05$; QS: $p<0.05$; AW: $p<0.02$ ). This decline, however, was only significant in term babies.

$\mathrm{PtcCO}_{2}$ variability did not change as a function of age, nor did
Table 1. Clinical characteristics

\begin{tabular}{lcc}
\hline & $\begin{array}{c}\text { Preterm } \\
(n=19)\end{array}$ & $\begin{array}{c}\text { Term Control } \\
(n=14)\end{array}$ \\
\hline Birth weight $(\mathrm{g})$ & 1728.2 & 3520.9 \\
Mean & $(321.2)$ & $(301.2)$ \\
SD & $1210-2250$ & $3062-4026$ \\
Range & & \\
Gestational age (wk) & $32.2(1.8)$ & $39.9(1.0)$ \\
Mean (SD) & $28-35$ & $39-42$ \\
Range & & \\
Race & 16 & 2 \\
Hispanic & 2 & 1 \\
Black & 1 & 10 \\
Caucasian & & 1 \\
Asian & $14 / 5$ & $5 / 9$ \\
Sex (M/F) & & \\
Apgar (median) & 8 & 9 \\
1 min & 8 & 9 \\
5 min & $1-9$ & $2-8$ \\
Maternal gravida & 7 & 2 \\
Cesarean section & &
\end{tabular}

Table 2. Percentage of sleep and waking as a function of age and study group

\begin{tabular}{cccc}
\hline State & QS & AS & AW \\
\hline 40wk & & & \\
Preterm & & & \\
Apneic* & 23.2 & 46.5 & 18.8 \\
Nonapneic & 24.0 & 43.0 & 22.5 \\
44 wk/1 mo & & & \\
Preterm & & & \\
Apneic & 27.7 & 39.9 \\
Nonapneic & 25.5 & 30.5 & 22.0 \\
Term control & 25.0 & 47.3 & 32.8 \\
52 wk/3 mo & & & \\
Preterm & & & \\
Apneic & 32.2 & 43.0 & 16.9 \\
Nonapneic & 35.7 & 39.7 & 15.3 \\
Term control & 31.5 & 40.0 & 19.6 \\
6 mo & & & \\
Term control & 41.2 & 27.8 & 21.5 \\
\hline
\end{tabular}

* Apneic in the nursery before discharge, at the time of monitoring asymptomatic.

$\dagger$ Significantly different at $p<0.05$.

the transient rises and drops of $>2 \mathrm{SD}$ in $\mathrm{PtcCO}_{2}$ levels. These occurred on average between 1 and 1.5 times per min and varied in the preterm group between 0 and 8 per min, compared to 0 11 times per min in the control group.

Transcutaneous gases as function of state. There was a significant state effect in the levels of $\mathrm{PtcO}_{2}$ in the preterm group $(F=$ $18.10, d f 3,9, p<0.001)$ and the control group $(F=8.32$, $d f$ $3,12, p<0.03)$. This main effect was entirely attributable to the elevated levels during AW compared to both sleep states. The $\mathrm{PtcO}_{2}$ level was not significantly different in AS compared to QS at any age (Table 3 ). The variability of $\mathrm{PtCO}_{2}$ showed a significant state effect as well $(F=29.29$, df $3,5, p<0.001)$. The highest variability was seen during AW, followed by that of AS and then QS (Table 3). The maximum number of relative drops, however, and the absolute decreases in $\mathrm{PtcO}_{2}$ exhibited no preference for any sleep state.

$\mathrm{PtcCO}_{2}$ levels were elevated in QS compared to AS at all ages and in both study groups. As with $\mathrm{PtcO}_{2}$ variability, the variability of $\mathrm{PtCCO}_{2}$ was significantly higher during AS compared to QS. There was no one state in the term infant in which hypercapnic values occurred more frequently. In the preterm group at $40 \mathrm{wk}$, however, more than half (56\%) of the infants' mean $\mathrm{PtcCO}_{2}$ levels during QS reached what are considered hypercapnic values. 
QUIET SLEEP

TERM INFANT 3 MONTHS

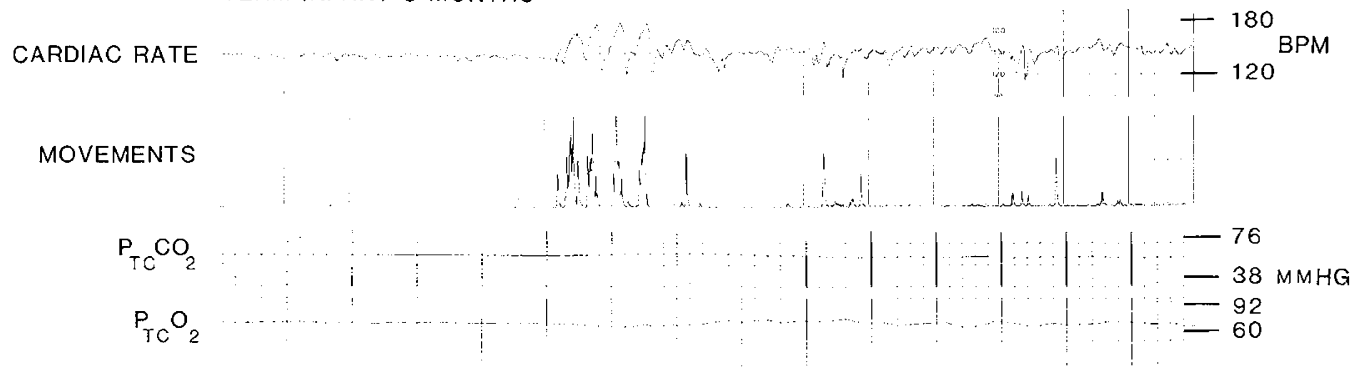

TEMP CONTROL

RESP (CO2)

RESP RATE

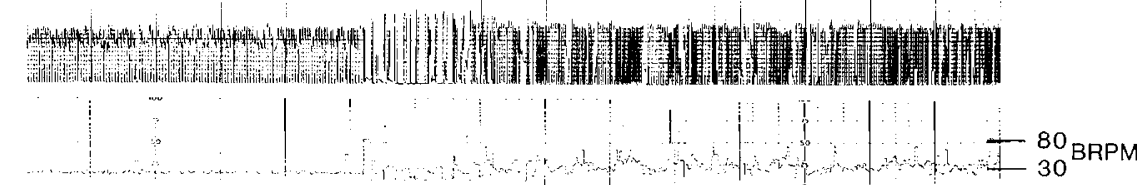

Fig. 3. Representative sample of the slow polygraphic recording in a 3-mo-old term infant. On a minute to minute basis, $\mathrm{PtcO}_{2} \mathrm{rose}$ while $\mathrm{PtcCO}_{2}$ declined, as shown here at the transition from QS to AS. Mean values of $\mathrm{PtcCO}_{2}$ were consistently elevated during QS compared to AS (38 mm $\mathrm{Hg}$ $=5.13 \mathrm{kPa} ; 76 \mathrm{~mm} \mathrm{Hg}=10.26 \mathrm{kPa} ; 60 \mathrm{~mm} \mathrm{Hg}=8.1 \mathrm{kPa} ; 92 \mathrm{~mm} \mathrm{Hg}=12.42 \mathrm{kPa}$ ).

Table 3. Transcutaneous $\mathrm{O}_{2}$ and $\mathrm{CO}_{2}$ levels and variability in each study group

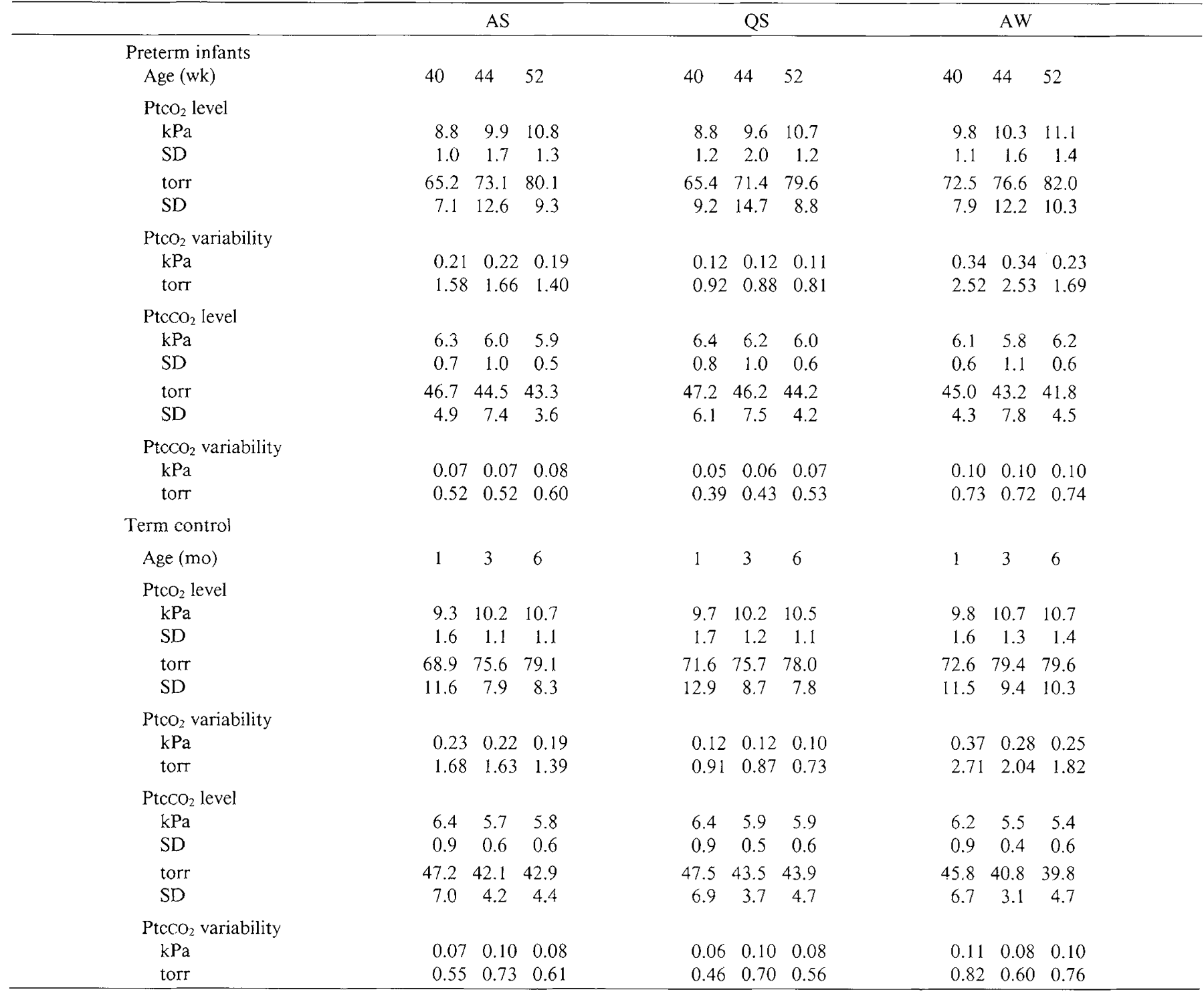




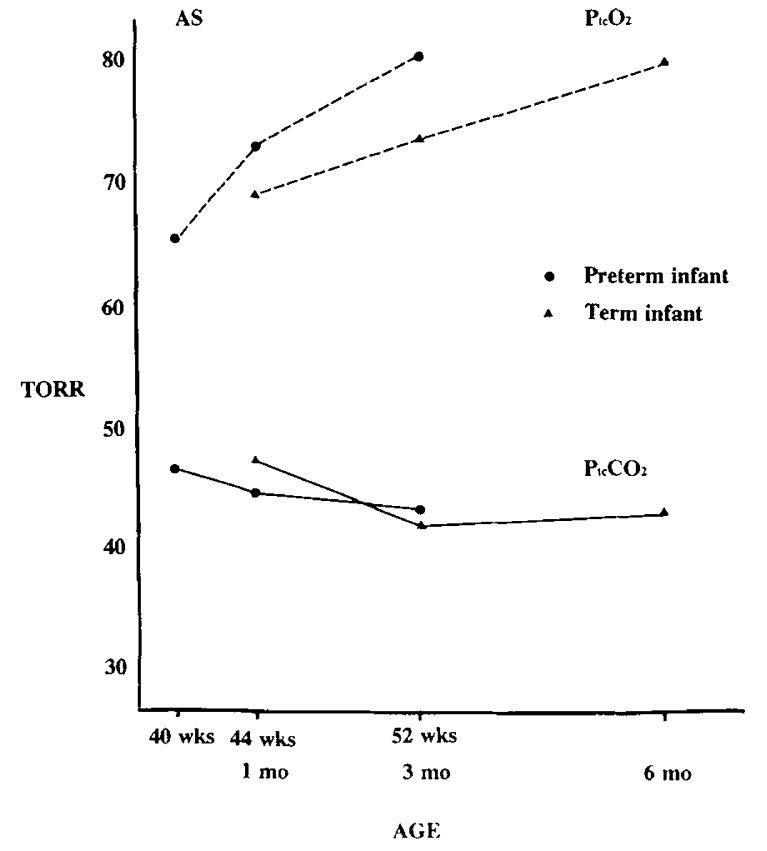

Fig. 4. The rise in $\mathrm{PtcO}_{2}$ and the concomitant decline of $\mathrm{PtcCO}_{2}$ between $40 \mathrm{wk}$ and $3 \mathrm{mo}$ is shown during AS in preterm and term control infants $(10$ torr $=1.35 \mathrm{kPa} ; 30$ torr $=4.05 \mathrm{kPa})$.

\section{DISCUSSION}

Computer analysis of systematically obtained polygraphic data revealed an increase in $\mathrm{PtcO}_{2}$ levels between 40 wk and 3 mo of age, coupled with a simultaneous decline in $\mathrm{PtcCO}_{2}$ levels. At the same conceptional age, preterm infants exhibited similar levels of both $\mathrm{PtcO}_{2}$ and $\mathrm{PtcCO}_{2}$ as term control. Although wakefulness induced $\mathrm{PtcO}_{2}$ levels higher than those in sleep, no differences were seen in levels of $\mathrm{PtCO}_{2}$ during AS and QS. Variability of $\mathrm{PtcO}_{2}$, however, was invariably higher during AS than QS. In contrast, a sleep state modulation of both the level and variability of $\mathrm{PtcCO}_{2}$ was observed at every age. $\mathrm{PtcCO}_{2}$ levels were higher during QS and the variability lower.

The values for the levels of $\mathrm{PtcO}_{2}$ are quite comparable to those obtained by others $(6,10-13,16)$ despite our temperature setting of $43.5^{\circ} \mathrm{C}, 0.5^{\circ} \mathrm{C}$ lower than customary levels. For instance, Mok et al. (16) reported mean $\mathrm{PtcO}_{2}$ values for preterm infants in QS and $\mathrm{AS}$ between $39-46$ wk PCA as 9.0 and $9.1 \mathrm{kPa}(67$ and 68 $\mathrm{mm} \mathrm{Hg}$ ); between 47 and 57 wk the values were 10.1 and 10.4 $\mathrm{kPa}(75$ and $77 \mathrm{~mm} \mathrm{Hg}$ ). Our data, based on minute by minute computer calculations, were 9.6 and $10.0(71$ and $74 \mathrm{~mm} \mathrm{Hg})$ at $44 \mathrm{wk}$ and 10.5 and $10.5 \mathrm{kPa}(80 \mathrm{~mm} \mathrm{Hg})$ at $52 \mathrm{wk}$.

During sleep, decreases in $\mathrm{PtcO}_{2}$ in excess of $2.0 \mathrm{kPa}(15 \mathrm{~mm}$ $\mathrm{Hg}$ ) declined with age. They were observed in about one third of the youngest control infants and in less than $10 \%$ of the 3 -moold infants and were absent at 6 mo. The fact that during wakefulness such variations are so abundant implies that these drops are generally benign. The similarity in the incidence of these $\mathrm{PtcO}_{2}$ drops between term control infants and preterm infants is striking at corrected ages. This finding parallels the similarity in levels of $\mathrm{PtcO}_{2}$ at corrected ages in these two groups.

$\mathrm{PtcCO}_{2}$ was measured with an unheated electrode, a state-ofthe-art technique when we collected our data that is not currently being used clinically. The resultant data are unique because undisturbed skin $\mathrm{PCO}_{2}$ is provided; local heating has not altered local metabolism nor increased $\mathrm{PCO}_{2}$ production. In our normal healthy infants, comparison with arterial values was not warranted. Such a study was, however, performed previously and had yielded a correlation coefficient comparable to those obtained by others $(18,23,25)$. Furthermore, the use of this unheated sensor does not preclude a valid comparison between study groups, ages, or sleep states. Transcutaneous tissue $\mathrm{PCO}_{2}$ measured with an unheated sensor was found to be an average of $1.22 \mathrm{kPa}(9 \mathrm{~mm} \mathrm{Hg})$ higher than arterial values based on the formula derived with the same sensor in another group of infants (23). Our results are similar to those of Bentele et al. (10) when corrected for transcutaneous-arterial differences. Using this correction for the unheated sensor, we found a substantial number of infants who exhibited mean adjusted $\mathrm{PtcCO}_{2}$ values in excess of $6.75 \mathrm{kPa}(50 \mathrm{~mm} \mathrm{Hg})$. In light of these findings, limits for hypercapnia based on transcutaneous values $[>6.75 \mathrm{kPa}(50 \mathrm{~mm}$ $\mathrm{Hg})]$ need to be reevaluated.

In preterm and term infants during the first week of life, Hanson and Okken (6) reported a higher level of $\mathrm{PtcO}_{2}$ in QS than in AS. In our study, where the infants were at least 4 wk old, differences of $\mathrm{PtcO}_{2}$ during various states were restricted to variability and were not seen in levels. It is almost certain that these differences in findings are attributable to maturation, because Mok et al. (13) reported that the level of $\mathrm{PtcO}_{2}$ in QS was higher than in AS in their youngest group, a difference that disappeared after the first week of life. Lastly, Martin et al. (18) reported higher $\mathrm{PtCCO}_{2}$ levels in QS than in AS in term newborns, a difference that persisted until 6 mo according to our data. Thus, state differences in $\mathrm{PtCO}_{2}$ continue in older infants, whereas those in $\mathrm{PtcO}_{2}$ seem to disappear early. Considerable evidence has been accumulating that breathing regulation in AS is not the same as that in QS $(1,2)$. A lowered $\mathrm{PtcCO}_{2}$ in $\mathrm{AS}$ indicates an increase in alveolar ventilation. In contrast, QS is characterized by a relative hypoventilation and an increased $\mathrm{PCO}_{2}$ threshold (18).

It is generally assumed that after neonatal adjustment, the infant's chemoreceptor reflexes are stable. However, transcutaneously measured $\mathrm{PO}_{2}$ continues to rise between 1 and 3 mo in both term and preterm infants. This rise occurs despite the thickening of the skin (13). It may be a result of improved matching of ventilation and perfusion due to a more stable rib cage (11), or it may be due to lung development (26). The rise represents an even larger increase in arterial values because in older infants $\mathrm{PtcO}_{2}$ increasingly underestimates arterial $\mathrm{O}_{2}$ tension (27).

In our study the $\mathrm{PtcCO}_{2}$ declined between 1 and 3 mo of age in term infants, a finding not reported before. Hazinski et al. (28) found a continued adjustment of chemoreceptor function during the first 2 mo of life in preterm infants before nursery discharge. Bryan (29) recently described a clear increase with age of the ventilatory response to $\mathrm{PCO}_{2}$ in normal term controls and siblings of infants with sudden infant death syndrome. Therefore, our data supports the idea that adjustments in the chemoreceptor system continue to take place beyond the first weeks of life.

In conclusion, few differences were found between term and preterm infants when corrected for gestational age. $\mathrm{PtcCO}_{2}$ but not $\mathrm{PtcO}_{2}$ levels were modulated by sleep and wakefulness, with $\mathrm{PtcCO}_{2}$ being higher in QS than in AS. The most important findings were the evidence for continued regulatory changes in ventilatory control during the first 3 mo of life. These changes include a rise in levels of $\mathrm{PtcO}_{2}$, a reduction in levels of $\mathrm{PtcCO}_{2}$, decreased variability of $\mathrm{PtCO}_{2}$ in term infants, and a decline in the number of drops exceeding $2.03 \mathrm{kPa}(15 \mathrm{~mm} \mathrm{Hg})$, all suggesting increased stability of the system. Finally, a surprising number of hypercapnic values were seen in the youngest group, especially during QS, and these disappeared with increasing age.

Acknowledgments. The authors thank Lori Judson, R.N., M.S., Maria Elena Ruiz, R.N., M.S., Jane Peckham, Kristin Moore, and Alan Keys for their contribution to the data collection and data analyses.

\section{REFERENCES}

1. Jansen AH 1983 Development of respiratory control. Physiol Rev 63:437-483 2. Walker D 1984 Peripheral and central chemoreceptors in the fetus and newborn. Annu Rev Physiol 46:687-703

3. Rigatto HJ, Brady JP, De la Torre Verduzco R 1975 Chemoreceptor reflexes 
in preterm infants $\mathrm{I}$. The effect of gestational and postnatal age on the ventilatory response to inhalation of $100 \%$ and $15 \%$ oxygen. Pediatrics 50:219-228

4. Rigatto H, Kalapesi Z, Leahy FN, Durand M, MacCallum M, Cates D 1982 Ventilary response to $100 \%$ and $15 \% \mathrm{O}_{2}$ during wakefulness and sleep in preterm infants. Early Hum Dev 7:1-10

5. Huch R, Huch A, Albani M, Gabriel M, Schulte FJ, Wolf H, Rupprath G, Emmrich P, Stechele U, Duc G, Bucher H 1976 Transcutaneous $\mathrm{PO}_{2}$ monitoring in routine management of infants and children with cardiorespiratory problems. Pediatrics 57:681-690

6. Hansen N, Okken A 1980 Transcutaneous oxygen tension of newborn infants in different behavioral states. Pediatr Res 14:911-915

7. Martin RJ, Okken A 1979 Arterial oxygen tension during active and quiet sleep in the normal neonate. J Pediatr 94:271-274

8. Wimberley $\mathrm{PD}$, Frii-Hansen 1981 The use of $\mathrm{T}_{\mathrm{cpO}}$ monitoring in neonatal intensive care. Dan Med Bull 28:37-40

9. Abu-Osba YK, Brouilette RT, Wilson SL, Thach BT 1982 Breathing pattern and transcutaneous oxygen tension during motor activity in preterm infants. Am Rev Respir Dis 125:382-387

10. Bentele KHP, Ancker U, Albani M 1987 Transcutaneous blood gases and sleep apnea profile in healthy preterm infants during early infancy. In: A Huch, $\mathrm{R}$ Huch, $\mathrm{G}$ Rooth (eds) Continuous Transcutaneous Monitoring. Plenum Press, New York, pp 89-94

11. Carse EA, Wilkinson AR, Whyte PL, Henderson-Smart DJ, Johnson P 1981 Oxygen and carbon dioxide tensions, breathing and heartrate in normal infants during the first six months of life. J Dev Physiol 3:85-100

12. Peirano P, Guidasci S, Monod N 1986 Effect of sleep position on transcutaneous oxygen tension in SIDS siblings. Early Hum Dev 13:303-312

13. Mok JY, McLaughlin FJ, Pintar M, Hak H, Almaro-Galvez R, Levison $H$ 1986 Transcutaneous monitoring of oxygenation: what is normal? J Pediatr 108:365-371

14. Lee D, Caces R, Kwiatkowski K, Cates D, Rigatto H 1987 A developmental study on types and frequency distribution of short apneas (3-15 seconds) in term and preterm infants. Pediatr Res 22:344-349

15. Southall DP, Bignall S, Stebbens VA, Alexander JR, Rivers RPA, Lissauer T 1987 Pulse oximetry and transcutaneous arterial oxygen measurements in neonatal and pediatric intensive care. Arch Dis Child 62:882 -888

16. Mok JYQ, Hak H, McLaughlin FJ, Pintar M, Canny GJ, Levison H 1988 Effect of age and state of wakefulness on transcutaneous oxygen values in preterm infants: a longitudinal study. J Pediatr 113:706-709

17. Vyas H, Helms P, Cheriyan G 1988 Transcutaneous oxygen monitoring beyond the neonatal period. Crit Care Med 16:844-847

18. Martin RJ, Herrell N, Pultusker M 1981 Transcutaneous measurement of carbon dioxide tension: effect of sleep state in term infants. Pediatrics 67:622 625

19. Hoppenbrouwers T, Hodgman JE, Arakawa K, Durand M, Cabal L 1991 Polygraphy after discharge in preterm infants with and without apnea in the nursery. Neuropediatrics (in press)

20. Hofmann E, Havens B, Geidel S, Hoppenbrouwers T 1977 Long-term continuous monitoring of multiple physiological parameters in newborn and young infants: procedural manual. Acta Paediatr Scand (suppi) 266: I-24

21. Hoppenbrouwers T, Harper RM, Hodgman JE, Sterman MB, McGinty DJ 1978 Polygraphic studies of normal infants during the first six months of life. II. Respiratory rate and variability as a function of state. Pediatr Res $12: 120-125$

22. Hoppenbrouwers T, Jilek J, Arakawa K, Stodick A, Cabal L, Hodgman JE 1983 A system for monitoring cardiorespiratory variables and transcutaneous blood gases during sleep in the newborn and young infant. In: Van Bemmel $\mathrm{JH}$, Ball MJ, Wigertz O (eds) Medinfo-83 IFIP-IMIA. North Holland, Amsterdam, NY, pp 644-647

23. Cabal L, Cruz H, Plajstek C, Yeh S, Siassi B, Hodgman JE 1981 Factors affecting heated transcutaneous $\mathrm{PO}_{2}$ and unheated $\mathrm{PCO}_{2}$ in preterm infants. Crit Care Med 9:298-304

24. Dixon WJ 1973 BMD Biomedical Computer Programs. University of California Press, Los Angeles

25. Hansen TN, Tooley WH 1979 Skin surface carbon dioxide tension in sick infants. Pediatrics 64:942-945

26. Martinez FD 1991 Sudden infant death syndrome and small airway occlusion: facts and a hypothesis. Pediatrics 87:190-198

27. Hamilton PA, Whitehead MD, Reynolds EOR 1985 Underestimation of arterial oxygen tension by transcutaneous electrode with increasing age in infants. Arch Dis Child 60:1162-1165

28. Hazinski TA, Severinghaus JW, Marin WS, Tooley WH 1984 Estimation of ventilatory response to carbon dioxide in newborn infants using skin surface blood gas electrodes. J Pediatr 105:389-393

29. Bryan C 1989 Respiratory control. In: RM Harper, HJ Hoffman (eds) Sudden Infant Death Syndrome, Risk Factors and Basic Mechanisms. PMA Publishing Co, New York, pp 249-256

\section{APPENDIX}

Let

$$
\begin{aligned}
\mathrm{m}(\mathrm{t}) & =\text { measurement at time } \mathrm{t} \\
\mathrm{L}_{\mathrm{B}} & =\text { calibration low value at } \mathrm{t}=0 \\
\mathrm{H}_{B} & =\text { calibration high value at } \mathrm{t}=0 \\
\mathrm{~L}_{\mathrm{E}} & =\text { calibration low value at } \mathrm{t}=\mathrm{T} \\
\mathrm{H}_{\mathrm{E}} & =\text { calibration high value at } \mathrm{t}=\mathrm{T} .
\end{aligned}
$$

Then the drift is $\mathrm{L}_{\mathrm{E}}-\mathrm{L}_{\mathrm{B}}$ at $\mathrm{m}(\mathrm{T})=\mathrm{L}_{\mathrm{E}}$ and $\mathrm{H}_{\mathrm{E}}-\mathrm{H}_{\mathrm{B}}$ at $\mathrm{m}(\mathrm{T})=$ $\mathrm{H}_{\mathrm{E}}$.

If it is assumed that the drift is proportional to $t$ and linearly related to $m$ so that the drift at time $t$ is given by $(a+b m) t$, then the adjusted measurement $\mathrm{m}$ adj at time $\mathrm{t}$ is $\mathrm{m}_{\mathrm{adj}}=\mathrm{m}-(\mathrm{a}+$ bm)t. Because $\left(\mathrm{a}+\mathrm{b} \cdot \mathrm{H}_{\mathrm{E}}\right) \mathrm{T}=\mathrm{H}_{\mathrm{E}}-\mathrm{H}_{\mathrm{B}}$ and $\left(\mathrm{a}+\mathrm{b} \cdot \mathrm{L}_{\mathrm{E}}\right) \mathrm{T}=\mathrm{L}_{\mathrm{E}}-$ $\mathrm{L}_{\mathrm{B}}$, we can determine $\mathrm{a}$ and $\mathrm{b}$ as

$$
\begin{aligned}
& \mathrm{a}=\frac{\mathrm{H}_{E}\left(\mathrm{~L}_{E}-\mathrm{L}_{\mathrm{B}}\right)-\mathrm{L}_{E}\left(\mathrm{H}_{E}-\mathrm{H}_{\mathrm{B}}\right)}{\left(\mathrm{H}_{\mathrm{E}}-\mathrm{L}_{\mathrm{E}}\right) \mathrm{T}} \text { and } \\
& \mathrm{b}=\frac{\left(\mathrm{H}_{E}-\mathrm{H}_{\mathrm{B}}\right)-\left(\mathrm{L}_{\mathrm{E}}-\mathrm{L}_{\mathrm{B}}\right)}{\left(\mathrm{H}_{\mathrm{E}}-\mathrm{L}_{\mathrm{E}}\right) \mathrm{T}} .
\end{aligned}
$$

